\title{
Elemene inhibits osteosarcoma growth by suppressing the renin-angiotensin system signaling pathway
}

\author{
LIXIANG DING $^{1}$, GENAI ZHANG ${ }^{1}$, YU HOU ${ }^{1}$, JIAO CHEN ${ }^{1}$ and YUKUN YIN ${ }^{1,2}$ \\ ${ }^{1}$ Department of Spinal Surgery, Beijing Shijitan Hospital, Capital Medical University, Beijing 100038; \\ ${ }^{2}$ Department of Traditional Chinese Medicine, National Cancer Center/Cancer Hospital, Chinese Academy of \\ Medical Sciences, Peking Union Medical College, Beijing 100021, P.R. China
}

Received March 25, 2016; Accepted April 12, 2017

DOI: $10.3892 / \mathrm{mmr} .2017 .7965$

\begin{abstract}
Osteosarcoma remains the most prevalent primary malignant bone tumor in children and young adults globally. Therefore, novel and highly effective antitumor agents are urgently required. Elemene is a natural plant compound extracted from the medicinal Chinese herb, Rhizomazedoariae, which has been employed as an antitumor agent for the treatment of a number of tumors, including osteosarcoma. However, the mechanisms underlying its antitumor effect are currently unclear. The human osteosarcoma cell lines, MG-63 and U2OS, were employed in the present study. MTT, migration, transwell invasion and terminal deoxynucleotidyltransferase-mediated deoxy-UTP-fluorescein nick end-labeling assays were performed to evaluate cell viability, migration, invasion and apoptosis, respectively. Western blotting and immunohistochemistry analyses were performed to measure the levels of renin-angiotensin system (RAS) components. In order to evaluate the effect of elemene on tumor weight and volume, MG-63 and U2OS cells were injected into mice. Treatment of osteosarcoma cell lines, MG-63 and U2OS, with elemene led to the inhibition of cell viability, migration and invasion, as well as induction of cell apoptosis. In addition, elemene treatment downregulated the expression of a number of RAS components. The growth of osteosarcoma cell-transplanted tumors in nude mice and angiotensin II expression were inhibited by elemene treatment. The results of the present study indicate that the antitumor effects of elemene may partly be due to downregulation of the RAS signaling pathway, and that RAS may be a putative pharmacological target for osteosarcoma therapy.
\end{abstract}

Correspondence to: Dr Yukun Yin, Department of Spinal Surgery, Beijing Shijitan Hospital, Capital Medical University, 10 Tieyi Road, Yangfangdian Street, Haidian, Beijing 100038, P.R. China

E-mail: yin654790@163.com

Key words: elemene, osteosarcoma, renin-angiotensin system signaling pathway

\section{Introduction}

Although the incidence of osteosarcoma is low, accounting for $1 \%$ of all cancer diagnoses (1), osteosarcoma remains the most prevalent primary malignant bone tumor in children and young adults globally. It is predominant among children and adolescents and represents 5-10\% of malignancies in this age group (2). Despite advances in surgery and multiagent chemotherapy, the 5-year survival rate is $60-70 \%$ for patients with localized disease, and as low as $20-30 \%$ for patients with metastasis (3). Therefore, identifying novel, highly effective antitumor agents is urgently required.

Elemene (1-methyl-1-vinyl-2,4-diisopropenyl-cyclohexane) is extracted from the traditional Chinese medicinal herb Rhizomazedoariae and is considered as a novel anticancer drug (4). Elemene has been evaluated in clinical trials and is used for the effective treatment of a number of cancer types, including leukemia, glioma, non-small cell lung cancer, and cervical, breast and liver cancers (5-8). These previous studies have indicated that elemene may be a broad-spectrum anticancer agent, and therefore presents a potentially important chemotherapeutic agent. A previous study demonstrated that elemene inhibited the viability and induced apoptosis of human osteosarcoma cells in a doseand time-dependent manner, and the anticancer effects of elemene were reduced by the hypoxia-inducible factor 1 protein (9). An additional study revealed that all essential components of the renin-angiotensin system (RAS) axis, including angiotensin-(1-7) [Ang-(1-7)] generating proteases and the putative Ang-(1-7) receptor (Mas) are expressed in U2OS and MNNG-HOS osteosarcoma cell lines (10). Therefore, it is possible that the mechanism underlying the effects of elemene on osteosarcoma may be associated with the RAS signaling pathway.

The aim of the present study was to investigate the precise mechanisms underlying the effects of elemene on osteosarcoma development, and to determine whether this mechanism may be associated with the RAS signaling pathway. The results revealed that elemene inhibited the growth of the osteosarcoma cell lines MG-63 and U2OS potentially via the RAS singling pathway. Therefore, the present study provides a potential therapeutic target for the treatment of osteosarcoma. 


\section{Materials and methods}

Cell culture. The human osteosarcoma cell lines MG-63 and U2OS were obtained from Type Culture Collection of the Chinese Academy of Sciences (Shanghai, China). Cells were cultured in high-glucose Dulbecco's modified Eagle's medium (DMEM; Thermo Fisher Scientific, Inc., Waltham, MA, USA) supplemented with $10 \%$ fetal bovine serum (FBS; Thermo Fisher Scientific, Inc.), $100 \mathrm{U} / \mathrm{ml}$ penicillin G (Sigma-Aldrich; Merck KGaA, Darmstadt, Germany) and $100 \mathrm{U} / \mathrm{ml}$ streptomycin (Sigma-Aldrich; Merck KGaA), and maintained at $37^{\circ} \mathrm{C}$ and $5 \% \mathrm{CO}_{2}$. MG-63 and U2OS cells were then treated with $0,10,40,80$ and $160 \mu \mathrm{g} / \mathrm{ml}$ elemene (Dalian Jingang Pharmaceutical Co., Ltd., Dalian, China) for 48 or $72 \mathrm{~h}$, respectively.

Cell viability assay. MG-63 and U2OS cells were treated with $0,10,40,80$ and $160 \mu \mathrm{g} / \mathrm{ml}$ elemene for 48 or $72 \mathrm{~h}$, respectively. Cells were seeded in 96-well plates at a density of $1 \times 10^{4}$ cells/well and incubated for $24 \mathrm{~h}$. Cell viability was evaluated using an MTT assay kit (Sigma-Aldrich; Merck $\mathrm{KGaA}$ ) as previously described (11). Briefly, $10 \mu 1$ tetrazolium salt (MTT, $3 \mathrm{mg} / \mathrm{ml}$ ) was added to the culture medium for a $2 \mathrm{~h}$ incubation at $37^{\circ} \mathrm{C}$. Culture media was removed and cells were lysed in $100 \mu \mathrm{l}$ DMSO (Sigma-Aldrich; Merck KGaA) at room temperature for $10 \mathrm{~min}$. Microplates were read using a multiwell scanning spectrophotometer (Titertek-Berthold; Berthold Detection Systems GmbH, Pforzheim, Germany) at $540 \mathrm{~nm}$.

Determination of caspase-3 activity. The assay performed was based on the ability of the active enzyme to cleave the chromophore from the enzyme substrates of caspase- 3 and acetyl-Asp-Glu-Val-Asp-p-nitroanilide (Ac-DEVD-pNA) (12). The hydrolysis of the peptide substrate Ac-DEVD-pNA by caspase- 3 results in the release of the p-nitroaniline (pNA) moiety (12). pNA moiety is yellow, and the concentration may be detected by measuring the absorbance at a wavelength of $405 \mathrm{~nm}$; with its capacity, this can infer the activity of caspase-3 (12). MG-63 and U2OS cells (1x10\%/well) were seeded into 6-well plates, incubated at $37^{\circ} \mathrm{C}$ overnight, and then exposed to $0,10,40,80$ and $160 \mu \mathrm{g} / \mathrm{ml}$ elemene at room temperature for $72 \mathrm{~h}$. Caspase-3 activity was measured using a caspase-3 activity assay kit (Beyotime Institute of Biotechnology, Haimen, China) according to the manufacturer's instructions; the release of pNA was monitored at $405 \mathrm{~nm}$ using a standard curve of defined pNA solutions.

Migration assay. Cell migration assays were performed using 24-well Transwell plates $(8-\mu \mathrm{m}$ pore size; BD Biosciences, Franklin Lakes, NJ, USA), according to the manufacturer's instructions. Briefly, MG-63 and U2OS cells were treated with $0,10,40,80$ and $160 \mu \mathrm{g} / \mathrm{ml}$ elemene for $72 \mathrm{~h}$. Then, cells were trypsinized with $0.05 \%$ trypsin and washed 3 times in DMEM without FBS. A total of $5 \times 10^{4}$ cells were then suspended in $500 \mu 1$ DMEM without FBS and added to the upper chamber, while $750 \mu \mathrm{l}$ DMEM containing $10 \%$ FBS was placed in the lower chamber. The cells were incubated for $24-48 \mathrm{~h}$ at $37^{\circ} \mathrm{C}$ in a $5 \% \mathrm{CO}_{2}$ humidified incubator. The non-migrating cells were removed with cotton swabs and the migrated cells were fixed in $4 \%$ paraformaldehyde for $15 \mathrm{~min}$ at $4{ }^{\circ} \mathrm{C}$ and stained with $0.5 \%$ crystal violet at room temperature for $1 \mathrm{~h}$. Cells in at least 5 random microscopic fields (magnification, x100) were counted by light microscopy (LeicaDM4000; Leica Microsystems GmbH, Wetzlar, Germany), images were captured using a Nikon Eclipse 80i (Nikon Corporation, Tokyo, Japan) and analyzed with Image-Pro Plus computer software (version 4.0; Media Cybernetics, Inc., Rockville, MD, USA). All experiments were performed in duplicate and repeated three times.

Invasion assay. Transwell filters (Corning Incorporated, Corning, NY, USA) were coated with $3.9 \mu \mathrm{g} / \mu \mathrm{l}$ Matrigel (60-80 $\mu \mathrm{l})$. MG-63 and U2OS cells that treated with 0,10 , 40, 80 and $160 \mu \mathrm{g} / \mathrm{ml}$ elemene for $72 \mathrm{~h}$, were used for cell invasion determination. The cells $\left(2 \times 10^{4}\right.$ cells/well $)$ were resuspended in $100 \mu \mathrm{l}$ serum-free RPMI-1640 medium and added into the upper compartment of the chambers. Following $24 \mathrm{~h}$ of incubation at $37^{\circ} \mathrm{C}$, the cells migrating from the Matrigel into the pores of the inserted filter were fixed with $100 \%$ methanol (Sigma-Aldrich; Merck KGaA) for $30 \mathrm{~min}$ at room temperature, and stained with $50 \%$ hematoxylin (Sigma-Aldrich; Merck KGaA) at room temperature for $15 \mathrm{~min}$. The positively-stained cells were counted under three randomly selected visual fields at $\mathrm{x} 400$ magnification with a fluorescence microscope (SMZ1000; Nikon Corporation,), and analyzed with Image-Pro Plus computer software (version 4.0, Media Cybernetics, Inc.).

Analysis of cell apoptosis by Annexin V/propidium iodide (PI) staining. MG63 and U2OS cells were stained with Annexin V-fluorescent isothiocyanate (FITC) conjugate and PI to analyze cell apoptosis. MG63 and U2OS cells $\left(1 \times 10^{5}\right)$ were cultured in 24-well plates. Following overnight incubation, cells were treated with various concentrations of elemene $(0$, $10,40,80$ and $160 \mu \mathrm{g} / \mathrm{ml}$ ) for $72 \mathrm{~h}$ and collected by trypsinization with $0.05 \%$ trypsin. Cells were washed twice with $4^{\circ} \mathrm{C}$ PBS following centrifugation at $2,000 \times \mathrm{g}$ for $5 \mathrm{~min}$ at $4^{\circ} \mathrm{C}$, the cell pellets were suspended in $195 \mu$ lice-cold $1 \mathrm{X}$ binding buffer at a density of $\sim 1 \times 10^{6}$ cells $/ \mathrm{ml}$, and then incubated with $5 \mu \mathrm{l}$ Annexin V-FITC (Beyotime Institute of Biotechnology) for $10 \mathrm{~min}$ at room temperature in the dark. Following cell centrifugation at $1,000 \mathrm{x}$ g for $5 \mathrm{~min}$ at $4^{\circ} \mathrm{C}, 200 \mu \mathrm{l}$ ice-cold $1 \mathrm{X}$ binding buffer containing $10 \mu \mathrm{l}$ PI (BD Biosciences, San Jose, CA, USA) was added for flow cytometric analysis using the FACSCalibur flow fluorocytometer (BD Biosciences) for $1 \mathrm{~h}$. The data obtained were analyzed using CellQuest software (version 3.1; BD Biosciences).

Xenograft tumor model. Experiments involving mice were approved by the Institutional Animal Care and Use Committee of The Cancer Hospital of The Chinese Academy of Medical Sciences (Beijing, China). A total of 24 female BALB/c nude mice (4-6 weeks old, weighting 18-20 g, $n=6$ in each group) were purchased from The Shanghai Laboratory Animal Center, Chinese Academy of Sciences (Shanghai, China). Mice were housed in polystyrene cages (Two mice/cage) with free access to food and water, a 12-h light-darkness cycle, and an ambient temperature of $20-25^{\circ} \mathrm{C}$. MG-63 or U2OS cells $\left(5 \times 10^{6}\right)$ resuspended in $0.1 \mathrm{ml}$ DMEM were subcutaneously 
inoculated into the lower right flank of nude mice. When the developing tumors reached $100 \mathrm{~mm}^{3}$ in size, treatment was initiated by intraperitoneal injection of elemene $(50 \mathrm{mg} / \mathrm{kg})$ or normal saline $(1 \mathrm{mg} / \mathrm{kg})$ every other day for 21 days. Tumor size was measured at 10,12,16, 19 and 21 days, and the tumor volume (V) was calculated using the following formula: $\mathrm{V}=$ (length $\mathrm{x}$ width $\mathrm{x}$ height) $\mathrm{x} 0.5236$ (13). Following the last treatment of elemene, all mice were sacrificed and the tumors were weighed.

Immunohistochemical analysis. Following the last treatment of elemene, all mice were sacrificed and after weighing the tumors, all tissues were fixed in formalin for immunohistochemical analysis in order to detect the expression of angiotensin II (AngII), which was performed as described previously (14). Briefly, samples were fixed in $10 \%$ neutral formalin for $48 \mathrm{~h}$ at $4^{\circ} \mathrm{C}$, embedded in paraffin and cut into $4-\mu \mathrm{m}$ sections for immunohistochemical staining. Samples were incubated overnight at $4^{\circ} \mathrm{C}$ with anti-AngII antibody (1:50; cat. no. ab47831; Abcam, Cambridge, UK). The samples were then incubated for $1 \mathrm{~h}$ at room temperature with a biotinylated secondary antibody (1:200; Vector Laboratories, Burlingame, CA, USA; cat. no. BA-9200). The bound secondary antibody was then amplified using the Elite ABC kit (Vector Laboratories, Inc.), according to the manufacturer's instructions. The antibody-biotin-avidin-peroxidase complex was visualized using $0.02 \% 3,3$ 'diaminobenzidene staining for $10 \mathrm{~min}$ at room temperature. The sections were mounted onto gelatin-coated slides that were air-dried overnight at room temperature; the coverslips were then mounted using Permount medium (Thermo Fisher Scientific, Inc.) and imaged using a light optical microscope (Olympus Corporation, Tokyo, Japan).

Western blot analysis. MG-63 and U2OS cells that treated with different concentrations of elemene $(0,10,40,80$ and $160 \mu \mathrm{g} / \mathrm{ml}$ ) for $72 \mathrm{~h}$, were used for western blot analysis. Protein was collected from MG-63 and U2OS cellsusing radioimmunoprecipitation buffer (Santa Cruz Biotechnology, Inc., Dallas, CA, USA) containing protease inhibitors at $4^{\circ} \mathrm{C}$ for $30 \mathrm{~min}$. Protein concentrations were quantified using a Bio-Rad protein assay (Bio-Rad Laboratories, Inc., Hercules, CA, USA). Proteins $(30 \mu \mathrm{g})$ were separated by $8 \%$ SDS-PAGE and transferred to polyvinylidene difluoride membranes (Amersham; GE Healthcare, Chicago, IL, USA). The membranes were blocked in 5\% non-fat milk (Merck KGaA) overnight at $4^{\circ} \mathrm{C}$. Transferred membranes were then stained with the following primary antibodies: Anti-B-cell lymphoma 2 (Bcl-2; 1:1,000; cat. no. ab37899; Abcam), anti-Bcl-2-like protein 4 (Bax; 1:1,000; cat. no. ab32503; Abcam), anti-cleaved caspase-3 (1:500; cat. no. ab13847; Abcam), anti-procaspase-3 (1:1,000; cat. no. ab32150; Abcam), anti-renin (1:500; cat. no. ab180608; Abcam), anti-rennin receptor (1:1,000; cat. no. GTX114169; GeneTex, Inc., Irvine, CA, USA), anti-AngII (1:200; cat. no. EPR2931, Abcam), anti-ACE (1:200; cat. no. PB0089; Boster Biological Technology, Pleasanton, CA, USA) and anti- $\beta$-actin (1:200; cat. no. ab8227; Abcam) overnight at $4^{\circ} \mathrm{C}$. Subsequently, protein bands were detected by incubation with a horseradish peroxidase-conjugated secondary antibody $(1: 1,000$; Beijing Zhongshan Golden Bridge Biotechnology Co., Ltd.; OriGene Technologies, Inc.,
Beijing, China; cat. no. A50-106P) at room temperature for $1 \mathrm{~h}$. Signals were detected using an enhanced chemiluminescence kit (Wuhan Booute Biotechnology Co., Ltd, Wuhan, China; cat. no. orb90504) and exposed to Kodak X-OMAT film (Kodak, Rochester, NY, USA). Each experiment was performed at least three times and the results were analyzed using Alpha View Analysis Tools (Alpha View SA software version 3.2.2; Protein Simple, San Jose, CA, USA).

Statistical analysis. Statistical analyses were performed using SPSS software version 16.0 (SPSS, Inc., Chicago, IL, USA). Data are expressed as the mean \pm standard deviation of at least three experiments. Statistical differences between two independent groups were analyzed using a Student's t-test, and differences among multiple groups were analyzed using one-way analysis of variance and post-hoc Tukey tests. $\mathrm{P}<0.05$ was considered to indicate a statistically significant difference.

\section{Results}

Elemene inhibits the viability, migration and invasion of MG-63 and U2OS cells. Human osteosarcoma MG-63 and U2OS cells were treated with $0,10,40,80$ and $160 \mu \mathrm{g} / \mathrm{ml}$ elemene for 48 or $72 \mathrm{~h}$. The results demonstrated that elemene inhibited the viability of MG-63 and U2OS cells in dose- and time-dependent manners (Fig. 1A). The Transwell migration assay also revealed that elemene inhibited the migration of MG-63 and U2OS cells in a dose-dependent manner (Fig. 1B). In addition, a significantly reduced level of invasion in MG-63 cells treated with 80 and $160 \mu \mathrm{g} / \mathrm{ml}$ elemene, and U2OS cells treated with $160 \mu \mathrm{g} / \mathrm{ml}$ elemene was observed (Fig. 1C). MG-63 cells were more sensitive to elemene when compared with U2OS cells, as MG-63 cells exhibited a greater repression of cell viability, migration and invasion following elemene treatment (Fig. 1). These results indicated that elemene demonstrated a significant antitumor effect on MG-63 and U2OS cells by inhibiting cell viability, migration and invasion.

Elemene induces apoptosis in MG-63 and U2OS cells. In order to investigate whether elemene effectively inhibits osteosarcoma cell growth via apoptosis induction, MG-63 and U2OS cells were treated with $0,10,40,80$ and $160 \mu \mathrm{g} / \mathrm{ml}$ elemene and cell apoptosis was measured. A significant increase in the number of apoptotic MG-63 cells was observed following treatment with 80 and $160 \mu \mathrm{g} / \mathrm{ml}$ elemene, and in U2OS cells following treatment with $160 \mu \mathrm{g} / \mathrm{ml}$ elemene (Fig. 2A). In addition, a dose-dependent increase in caspase 3 activity was observed in MG-63 and U2OS cells treated with elemene, which reached statistical significance at 80 and $160 \mu \mathrm{g} / \mathrm{ml}$ elemene in MG-63 cells and $160 \mu \mathrm{g} / \mathrm{ml}$ in U2OS cells (Fig. 2B). To further confirm that elemene induced apoptosis, western blotting was performed to detect the expression levels of apoptosis-associated proteins. Elemene significantly downregulated the level of Bcl-2 expression; however, elemene treatment upregulated the levels of BAX and cleaved caspase-3 in MG-63 and U2OS cells (Fig. 2C and D). Notably, MG-63 was more sensitive to elemene treatment when compared with U2OS cells. These results indicated that elemene inhibits cell viability potentially via apoptosis induction of human osteosarcoma cells. 
A

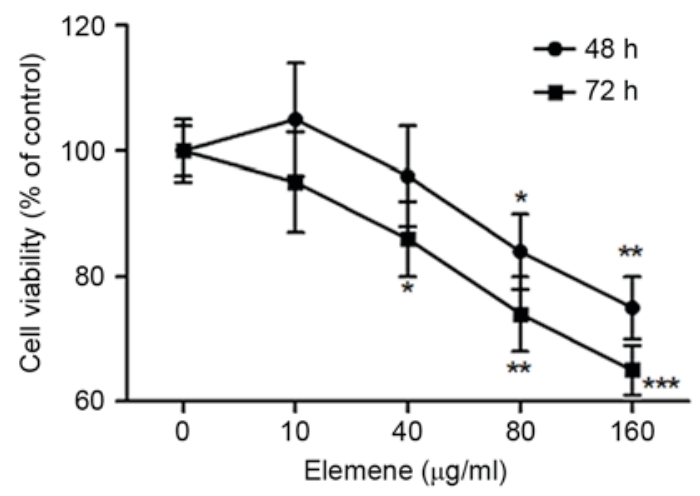

B

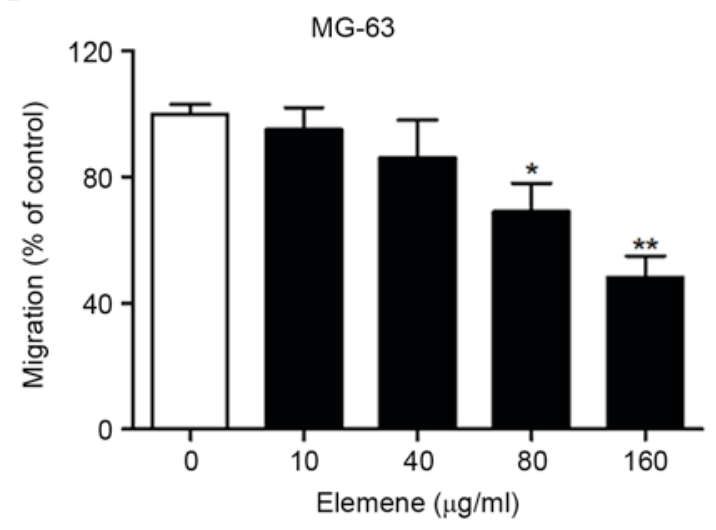

C

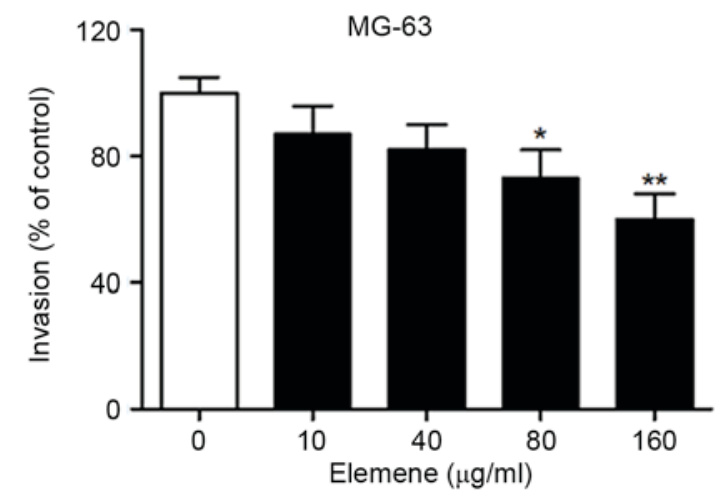

U2OS

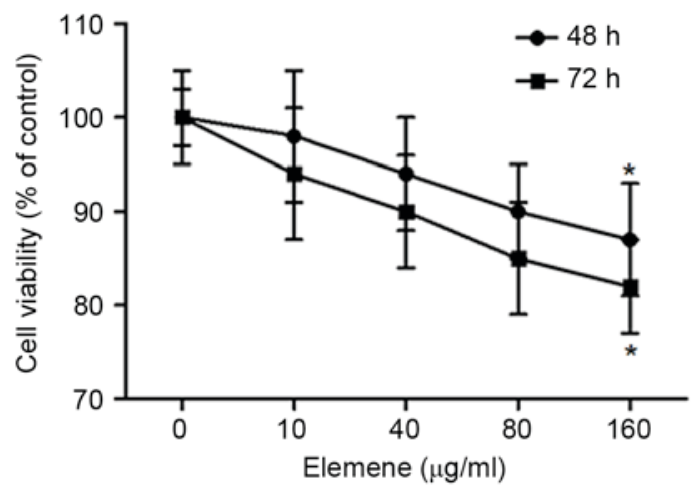

U2OS
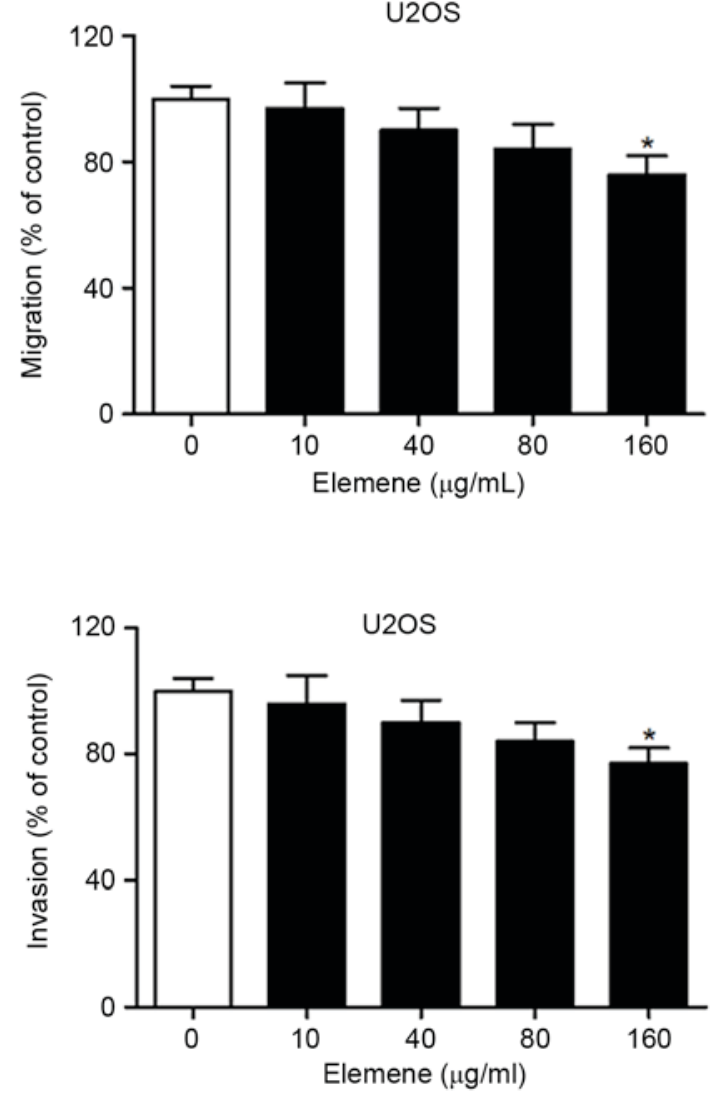

Figure 1. Elemene inhibited the viability, migration and invasion capabilities of MG-63 and U2OS cells. In MG-63 and U2OS cells, elemene inhibited (A) cell viability, (B) cell migration and (C) cell invasion in a dose-dependent manner. MG-63 and U2OS cells were exposed to $0,10,40,80$ or $160 \mu \mathrm{g} / \mathrm{ml}$ of elemene for 48 or $72 \mathrm{~h}$ prior to analysis of cell viability. The effect of elemene treatment on cell viability, migration and invasion was examined by comparing elemene-treated with untreated controls, and the results are expressed as the percentage of the control (100\%). The results are presented as the mean \pm standard deviation of three independent experiments. ${ }^{*} \mathrm{P}<0.05,{ }^{* *} \mathrm{P}<0.01$ and ${ }^{* * *} \mathrm{P}<0.001 \mathrm{vs} .0 \mu \mathrm{g} / \mathrm{ml}$ elemene-treated control.

Elemene inhibits the RAS signaling pathway in MG-63 and U2OScells. It has been well documented that the RAS signaling pathway is implicated in tumorigenesis (15). Therefore, the effects of elemene on the activity of this signaling pathway were investigated in the present study. MG-63 and U2OS cells were treated with $0,10,80$ or $160 \mu \mathrm{g} / \mathrm{ml}$ elemene, and the levels of renin, renin-receptor, AngII and ACE were detected by western blotting. The levels of renin, renin-receptor, AngII and ACE were downregulated by elemene treatment in a dose-dependent manner (Fig. 3A). In U2OS cells, renin and the renin-receptor were significantly downregulated in a dose-dependent manner following elemene treatment; however, AngII and ACE expression was not significantly altered (Fig. 3B). Elemene demonstrated a greater inhibitory effect on MG-63 cells when compared with U2OS cells, as the levels of renin, renin-receptor, AngII and ACE were significantly downregulated following treatment with $80 \mu \mathrm{g} / \mathrm{ml}$ elemene, whereas treatment with $160 \mu \mathrm{g} / \mathrm{ml}$ elemene significantly decreased renin and renin-receptor expression in U2OS cells (Fig. 3).

Elemene inhibits osteosarcoma development by suppressing the RAS signaling pathway inmouseosteosarcoma xenograft tumors. To provide direct evidence that the RAS signaling 


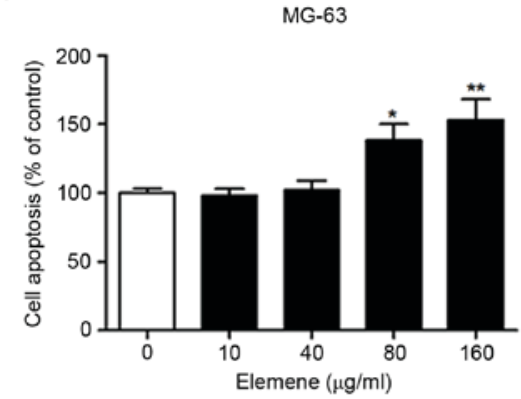

B

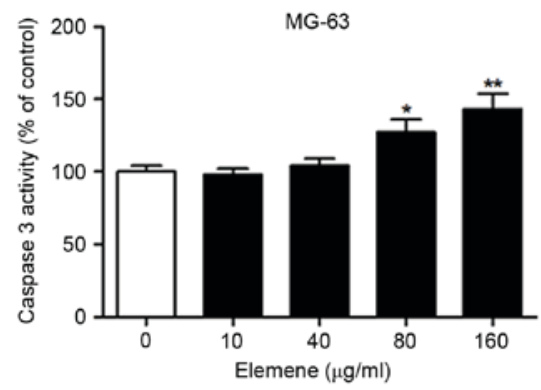

C

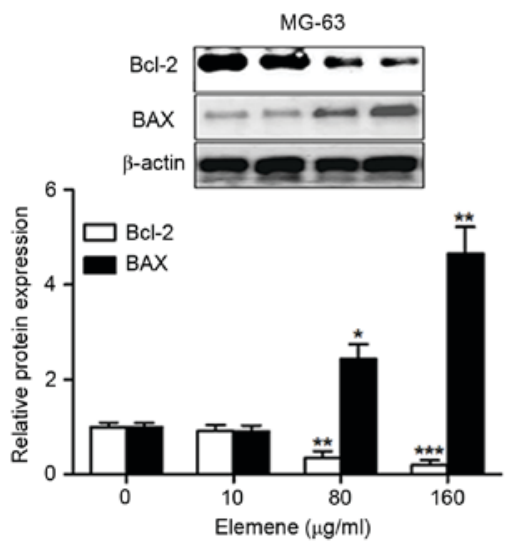

D
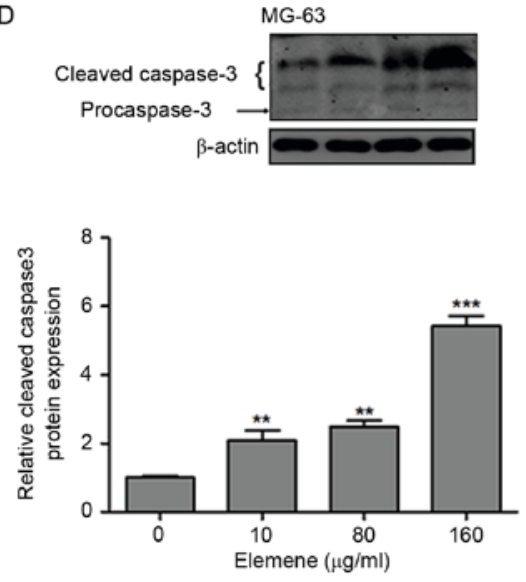

U2OS
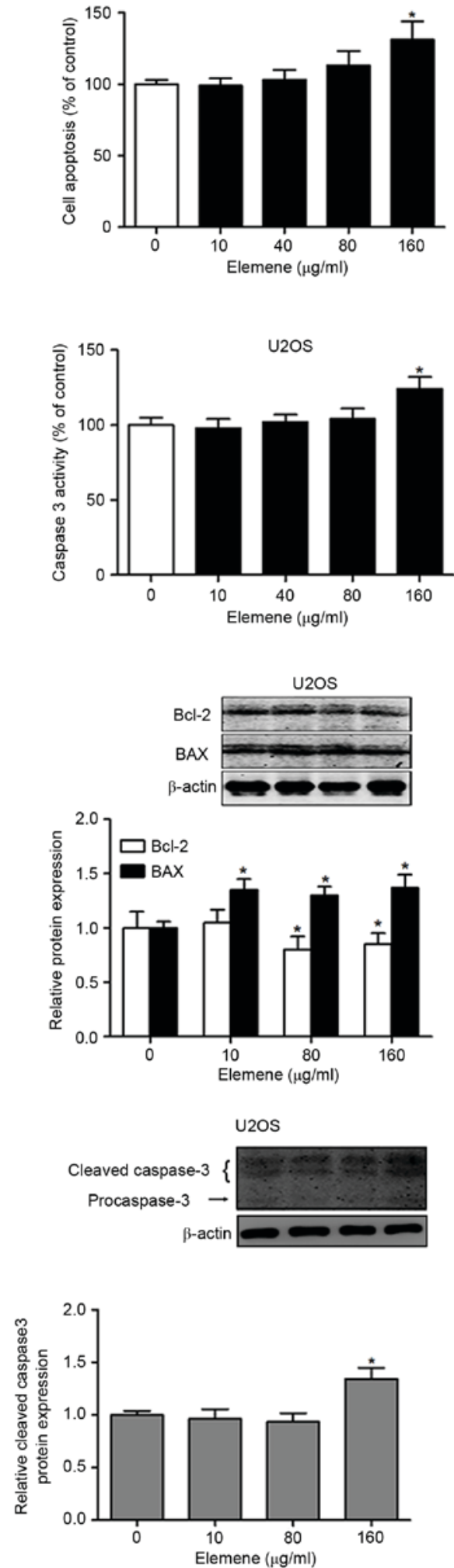

Figure 2. Elemene induced apoptosis in MG-63 and U2OS cells. (A) The cell apoptosis assay revealed that elemene induced MG-63 and U2OS cell apoptosis. (B) Elemene activated caspase-3 activity, (C) upregulated BAX expression and downregulated Bcl-2 levels, and (D) upregulated cleaved caspase-3 expression in MG-63 and U2OS cells. MG-63 and U2OS cells were exposed to 0,10, 40,80 or $160 \mu \mathrm{g} / \mathrm{ml}$ elemene for $72 \mathrm{~h}$. The results are presented as the mean \pm standard deviation of three independent experiments. ${ }^{*} \mathrm{P}<0.05,{ }^{* *} \mathrm{P}<0.01$ and ${ }^{* * *} \mathrm{P}<0.001 \mathrm{vs} .0 \mu \mathrm{g} / \mathrm{ml}$ elemene-treated controls. BAX, bcl-2-like protein 4 ; Bcl-2, B-cell lymphoma 2.

pathway is involved in the inhibitory effects of elemene on tumor development, MG-63 and U2OS cells were injected into the flank of nude mice, and then treated with $\mathrm{NaCl}$ or elemene.
The role of elemene in osteosarcoma development was first evaluated. As shown in Fig. 4A, tumor volume was significantly reduced in elemene-treated mice from days 16 to 21 following 
A
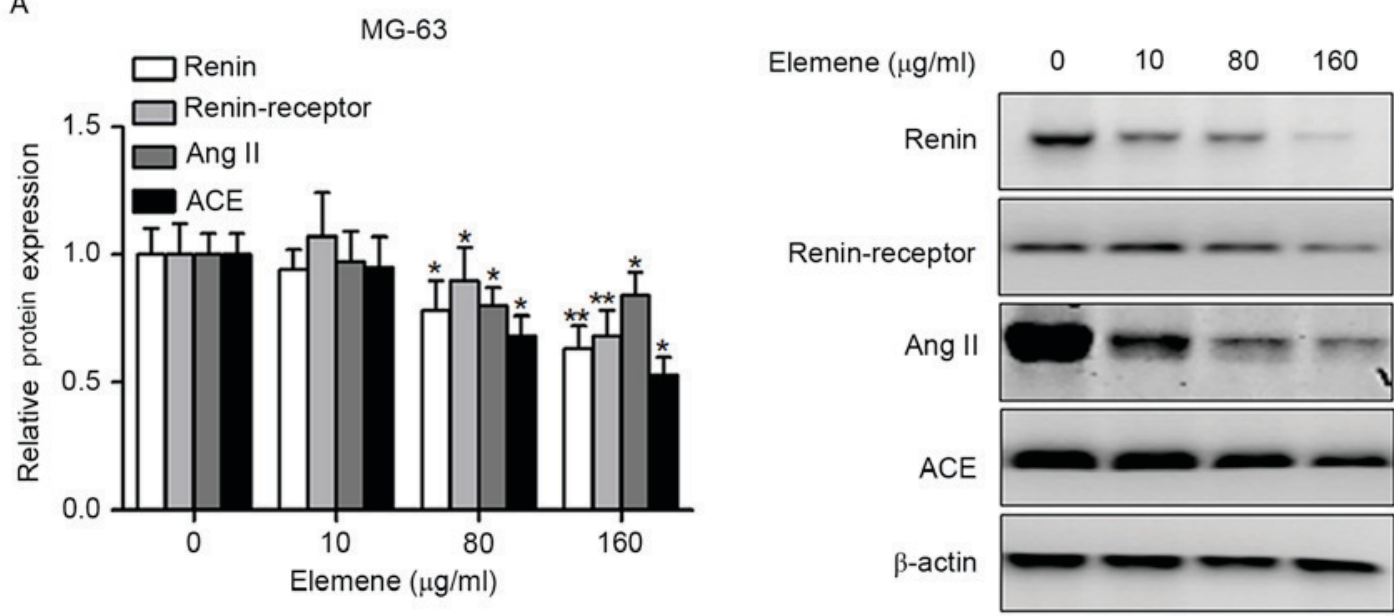

B

U2OS
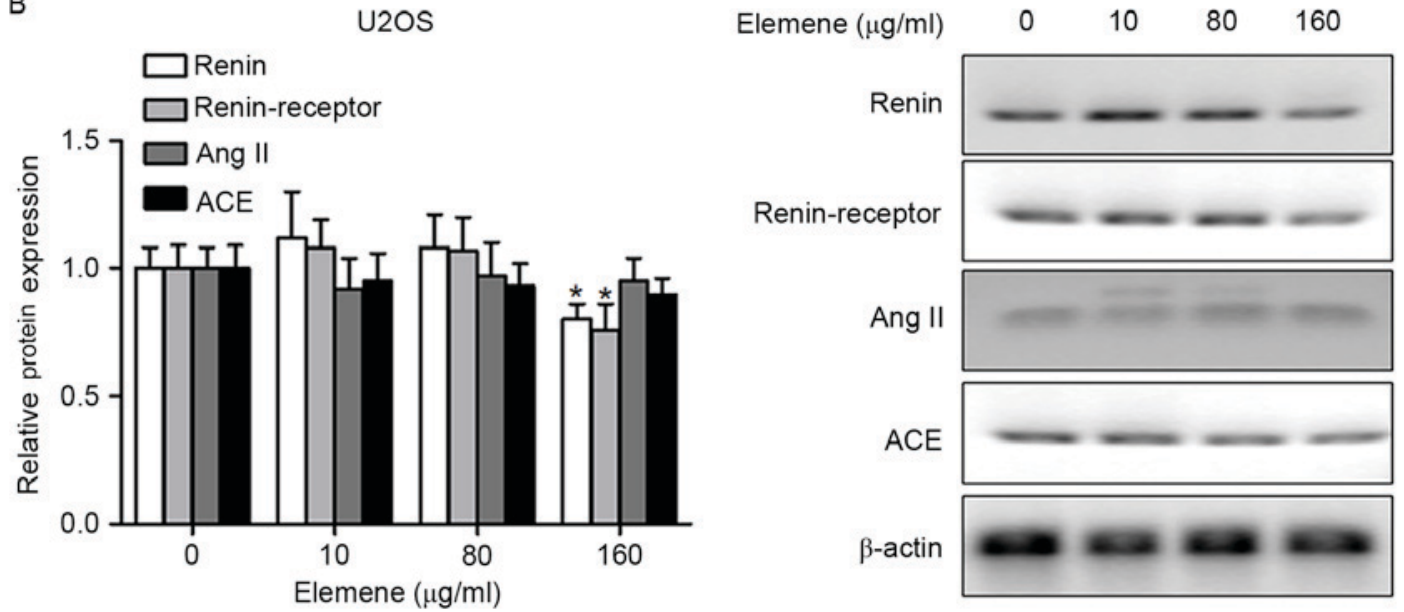

Figure 3. Elemene inhibited the RAS signaling pathway in MG-63 and U2OS cells. (A) Elemene inhibited the protein expression levels of renin, the renin-receptor, AngII and ACE in MG-63 cells. (B) In U2OS cells, elemene inhibited the protein expression of renin and the renin-receptor, whereas, it demonstrated no significant effect on AngII and ACE expression. The results are presented as the mean \pm standard deviation of three independent experiments. ${ }^{*} \mathrm{P}<0.05$ and ${ }^{* *} \mathrm{P}<0.01$ vs. $0 \mu \mathrm{g} / \mathrm{ml}$ elemene-treated control. RAS, renin-angiotensin system; AngII, angiotensin II; ACE, angiotensin-converting enzyme.

injection with MG-63 cells when compared with the controls $(\mathrm{P}<0.05$, day 16; $\mathrm{P}<0.01$, day 19; $\mathrm{P}<0.001$, day 21$)$. At 21 days post-injection, the tumor weight of the elemene-injected group was significantly lower when compared with the control group $(\mathrm{P}<0.01$; Fig. 4A). In mice injected with $\mathrm{U} 2 \mathrm{OS}$ cells and treated with elemene, tumor volume was significantly reduced at 21 days following treatment $(\mathrm{P}<0.05)$, and the tumor weight of the elemene-treated group was significantly reduced when compared with the control group ( $\mathrm{P}<0.05$; Fig. 4A).

Immunohistochemistry was used to detect the expression of AngII in MG-63 and U2OS xenograft tumors. Ang II is known to be an important component of the RAS signaling pathway (16). As exhibited in Fig. 4B, a significant reduction in the expression of AngII in MG-63 and U2OS cells was observed when compared with the control groups.

\section{Discussion}

The results of the present study demonstrate that elemene inhibits the viability, migration and invasion of human MG-63 and U2OS osteosarcoma cell lines, as well as induces apoptosis in these cell lines. In addition, the expression of pro-apoptotic proteins, cleaved caspase-3 and BAX were upregulated, whereas the expression of the anti-apoptotic protein, Bcl-2, was downregulated following elemene treatment of these cells. Further investigation revealed the potential involvement of the RAS signaling pathway in the inhibitory effect of elemene on osteosarcoma development, as renin, the renin-receptor, AngII and ACE were downregulated following elemene treatment. In addition, elemene was observed to downregulate the weight and volume of MG-63 and U2OS xenograft tumors, and reduce AngII expression. These results indicate that elemene may demonstrate the ability to inhibit osteosarcoma cell viability, migration and invasion, as well as induce cell apoptosis, partially via downregulation of the RAS signaling pathway.

Elemene is a novel plant-derived anticancer agent that exhibits a broad spectrum of antitumor activities in different cancers (17). In the present study, elemene was observed to exert its antitumor effects in osteosarcoma by inhibiting the viability, migration, invasion of osteosarcoma cells in vitro, as well as tumor volume and weight in vivo, potentially via induction of apoptosis. These results are consistent with previous studies demonstrating that elemene induces tumor 
A

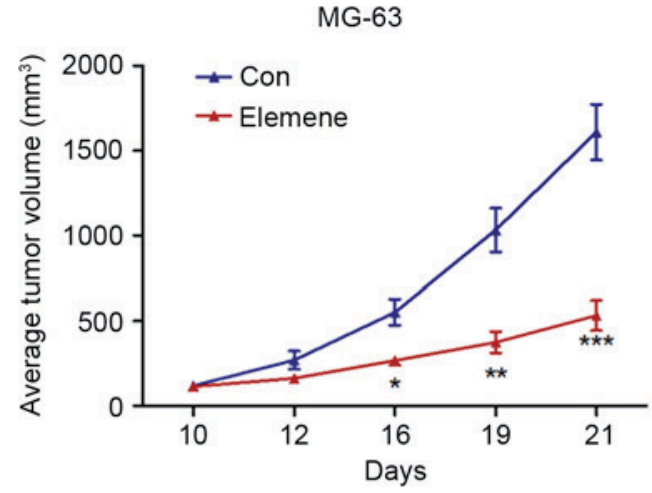

U2OS

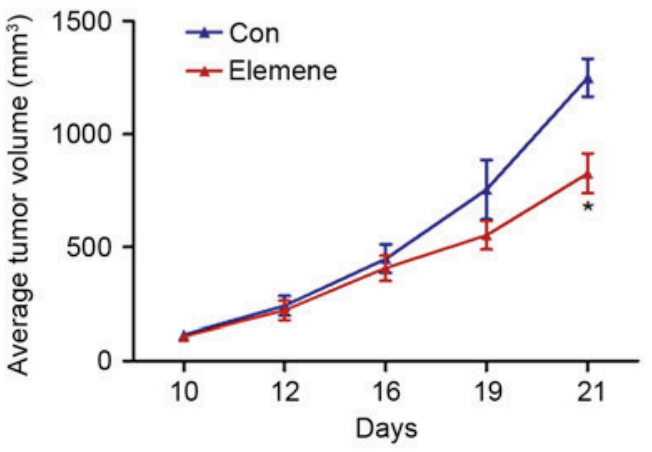

MG-63

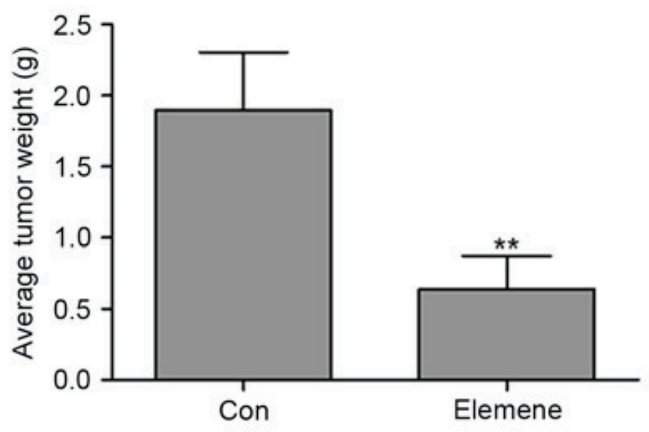

U2OS

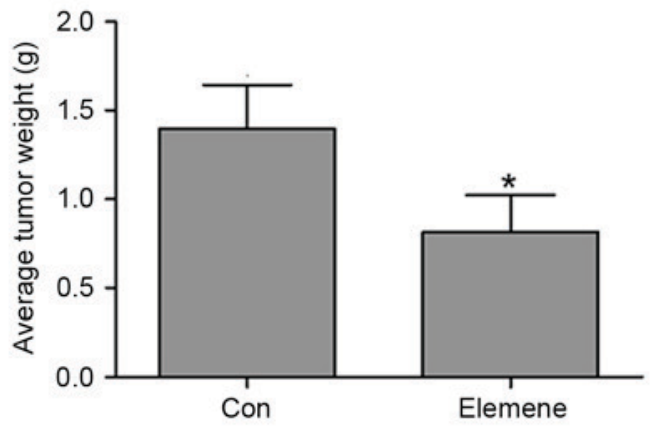

B
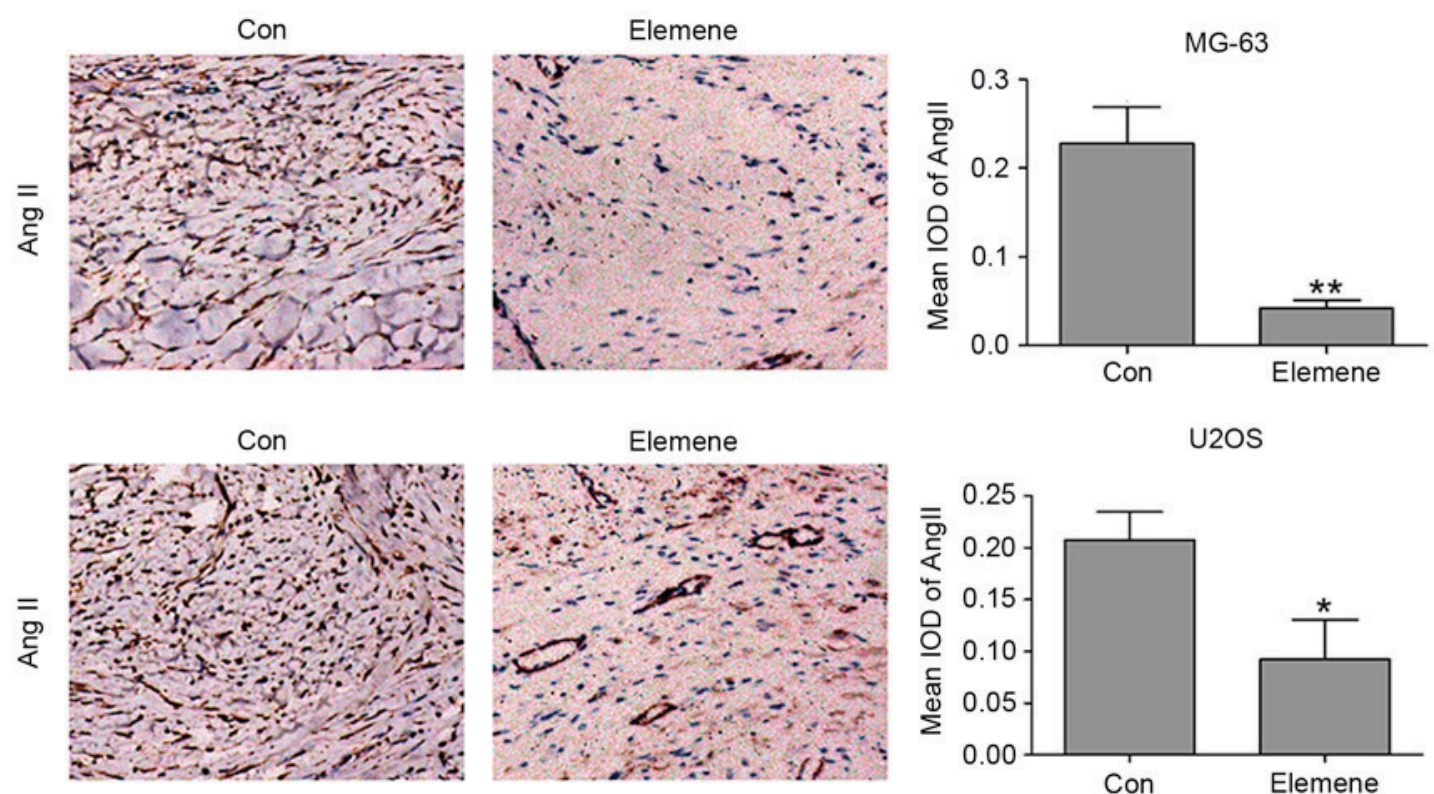

Figure 4. Elemene inhibited osteosarcoma development potentially via suppression of the RAS signaling pathway in mouse osteosarcoma xenograft tumors. Nude mice were injected with MG-63 or U2OS cells, followed by intraperitoneal injection of $\mathrm{NaCl}$ (Con) or elemene (50 mg/kg). (A) Elemene inhibited tumor volume and weight in the MG-63 and U2OS osteosarcoma mouse model. (B) Elemene inhibited AngII expression in the MG-63 and U2OS osteosarcoma mouse model (magnification, $\mathrm{x} 100$ ). The results are presented as the mean \pm standard deviation of three independent experiments. ${ }^{*} \mathrm{P}<0.05,{ }^{* *} \mathrm{P}<0.01$ and ${ }^{* * * *} \mathrm{P}<0.001$ vs. Con group. RAS, renin-angiotensin system; AngII, angiotensin II; Con, control; IOD, integrated optical density.

cell apoptosis and cell cycle arrest in the $\mathrm{G}_{2} / \mathrm{M}$-phase, as determined by morphological alterations, DNA fragmentation and flow cytometry analysis $(7,18,19)$. In addition, these previous studies have suggested that apoptosis and $\mathrm{G}_{2} / \mathrm{M}$-phase arrest induced by elemene may contribute to the inhibition of cell proliferation $(7,18,19)$. Furthermore, it has been demonstrated that elemene decreases the level of Bcl-2 protein, increases BAX and cleaved-caspase- 3 protein levels, and activates caspase-3 activity $(18,20,21)$.

The primary focus of previous investigations has been the intrinsic mechanisms underlying the antitumor activities of elemene. A previous study reported that elemene 
inhibited tumor growth in glioblastoma cells depending on the activation of the p38 mitogen-activated protein kinase pathway (22). In addition, elemene inhibited melanoma growth and metastasis by suppressing vascular endothelial growth factor (VEGF)-mediated angiogenesis (23). Furthermore, cell apoptosis induced by $\Delta$-elemene in colorectal adenocarcinoma cells was demonstrated to involve the mitochondrial-mediated pathway (24). The results of the present study suggest that the antitumor activity of elemene may be associated with the RAS signaling pathway, as elemene treatment downregulated renin, renin-receptor, AngII and ACE protein expression levels. This is consistent with a previous report, which revealed the role of the ACE2/Ang 1-7)/Mas axis in RAS-mediated effects on osteosarcoma cell proliferation (10).

RAS is mitogenic and angiogenic, and contributes to neoplastic growth in ovarian, prostate, lung, breast and pancreatic cancers (25). A number of RAS components, including renin, renin-receptor, ACE and AngII, are locally upregulated in tumors (26). In the present study, these molecules were significantly reduced by elemene treatment, suggesting that its antitumor effects may involve downregulation of the RAS signaling pathway. The implication of RAS in tumorigenesis is partially due to its robust angiogenic activity, which is mediated by the AngII/angiotensin type 1 receptor-dependent induction of proangiogenic factors, including angiopoietin 2, VEGF and platelet-derived growth factor (27-30), which affect key processes, including fibrosis, inflammation, proliferation and apoptosis (31). In the present study, AngII, the major effector peptide of the classical RAS signaling pathway, was downregulated by elemene treatment in human osteosarcoma cell lines and cell-transplanted tumors in nude mice.

In conclusion, the results of the present study indicated that elemene inhibits the growth of osteosarcoma cells potentially via the RAS signaling pathway. In addition, elemene suppressed tumor growth and AngII expression in MG-63 and U2OS cell-transplanted tumors in nude mice. The results therefore reveal a novel mechanism by which elemene may inhibit osteosarcoma cell growth.

\section{Acknowledgements}

The present study was financially supported by the Integrated Traditional Chinese and Western Medicine Project of Beijing Municipal Administration of Traditional Chinese Medicine (grant no. 2014-ZYJ03), and the China Postdoctoral Science Foundation Project (grant no. 2014M551001).

\section{References}

1. Mirabello L, Troisi RJ and Savage SA: Osteosarcoma incidence and survival rates from 1973 to 2004: Data from the surveillance, epidemiology, and end results program. Cancer 115: 1531-1543, 2009.

2. van den Berg H, Kroon HM, Slaar A and Hogendoorn P: Incidence of biopsy-proven bone tumors in children: A report based on the Dutch pathology registration 'PALGA'. J Pediatr Orthop 28: 29-35, 2008.

3. PosthumaDeBoer J, Witlox MA, Kaspers GJ and van Royen BJ: Molecular alterations as target for therapy in metastatic osteosarcoma: A review of literature. Clin Exp Metastasis 28: 493-503, 2011.
4. Zhan YH, Liu J, Qu XJ, Hou KZ, Wang KF, Liu YP and Wu B: $\beta$-Elemene induces apoptosis in human renal-cell carcinoma 786-0 cells through inhibition of MAPK/ERK and PI3K/Akt/mTOR signalling pathways. Asian Pac J Cancer Prev 13: 2739-2744, 2012

5. Wang G, Li X, Huang F, et al: Elemene, a novel anticancer drug, triggers cell death and enhances cisplatin sensitivity via induction of apoptosis and cell cycle arrest in human non-small cell lung cancer cells. Cancer Res 64: 689-689, 2004.

6. Kai LI, Cong X and Zhao X: The inhibitory effect of Xiaoaiping combined with elemene on cell proliferation and expression of Bcl-2 protein in cervix cancer HeLa cells. Chin J Clin Oncol 35: 705-561, 2008.

7. Li QQ, Wang G, Zhang M, Cuff CF, Huang L and Reed E: beta-Elemene, a novel plant-derived antineoplastic agent, increases cisplatin chemosensitivity of lung tumor cells by triggering apoptosis. Oncol Rep 22: 161-170, 2009.

8. Zhou HY, Shen JK, Hou JS, Qiu YM and Luo QZ: Experimental study on apoptosis induced by elemene in glioma cells. Ai Zheng 22: 959-963, 2003, (In Chinese).

9. Liang D, Yang M, Guo B, Yang L, Cao J and Zhang X: HIF-1a induced by $\beta$-elemene protects human osteosarcoma cells from undergoing apoptosis. J Cancer Res Clin Oncol 138: 1865-1877, 2012.

10. Ender SA, Dallmer A, Lässig F, Lendeckel U and Wolke C: Expression and function of the ACE2/angiotensin(1-7)/Mas axis in osteosarcoma cell lines U-2 OS and MNNG-HOS. Mol Med Rep 10: 804-810, 2014.

11. Fromigué O, Haÿ E, Modrowski D, Bouvet S, Jacquel A, Auberger P and Marie PJ: RhoA GTPase inactivation by statins induces osteosarcoma cell apoptosis by inhibiting p42/p44-MAPKs-Bcl-2 signaling independently of BMP-2 and cell differentiation. Cell Death Differ 13: 1845-1856, 2006.

12. Gatti L, Cossa G, Tinelli S, et al: Improved apoptotic cell death in drug-resistant non small cell lung cancer cells by TRAIL-based treatment. J Pharmacol Exp Ther: 194-201, 2013.

13. Ball DW, Jin N, Rosen DM, Dackiw A, Sidransky D, Xing M and Nelkin BD: Selective growth inhibition in BRAF mutant thyroid cancer by the mitogen-activated protein kinase kinase 1/2 inhibitor AZD6244. J Clin Endocrinol Metab 92: 4712-4718, 2007.

14. Krajewska M, Krajewski S, Epstein JI, Shabaik A, Sauvageot J, Song K, Kitada S and Reed JC: Immunohistochemical analysis of bcl-2, bax, bcl-X, and mcl-1 expression in prostate cancer. Am J Pathol 148: 1567-1576, 1996.

15. Bangalore S: Renin-angiotensin system inhibitors and risk of cancer. Trends Mol Med 17: 176-177, 2011.

16. Wang SR, Sang WK and Kim CJ: Overview of the Renin-Angiotensin system. Korean Circ J 37: 91-96, 2007.

17. Li X, Wang G, Zhao J, Ding H, Cunningham C, Chen F, Flynn DC, Reed E and Li QQ: Antiproliferative effect of beta-elemene in chemoresistant ovarian carcinoma cells is mediated through arrest of the cell cycle at the G2-M phase. Cell Mol Life Sci 62: 894-904, 2005

18. Wang G, Li X, Huang F, Zhao J, Ding H, Cunningham C, Coad JE, Flynn DC, Reed E and Li QQ: Antitumor effect of beta-elemene in non-small-cell lung cancer cells is mediated via induction of cell cycle arrest and apoptotic cell death. Cell Mol Life Sci 62: 881-893, 2005.

19. Zheng S, Yang H, Zhang S, Wang X, Yu L, Lu J and Li J: Initial study on naturally occurring products from traditional Chinese herbs and vegetables for chemoprevention. J Cell Biochem Suppl 27: 106-112, 1997.

20. Li QQ, Wang G, Huang F, Banda M and Reed E: Antineoplastic effect of beta-elemene on prostate cancer cells and other types of solid tumour cells. J Pharm Pharmacol 62: 1018-1027, 2010.

21. Li CL, Chang L, Guo L, Zhao D, Liu HB, Wang QS, Zhang $\mathrm{P}, \mathrm{Du} \mathrm{WZ}$, Liu X, Zhang HT, et al: $\beta$-elemene induces caspase-dependent apoptosis in human glioma cells in vitro through the upregulation of Bax and Fas/FasL and downregulation of Bcl-2. Asian Pac J Cancer Prev 15: 10407-10412, 2014.

22. Yao YQ, Ding X, Jia YC, Huang CX, Wang $Y Z$ and $X u$ YH: Anti-tumor effect of beta-elemene in glioblastoma cells depends on p38 MAPK activation. Cancer Lett 264: 127-134, 2008.

23. Chen W, Lu Y, Wu J, Gao M, Wang A and Xu B: Beta-elemene inhibits melanoma growth and metastasis via suppressing vascular endothelial growth factor-mediated angiogenesis. Cancer Chemother Pharmacol 67: 799-808, 2011. 
24. Xie CY, Yang W, Li M, Ying J, Tao SJ, Li K, Dong JH and Wang XS: Cell apoptosis induced by delta-elemene in colorectal adenocarcinoma cells via a mitochondrial-mediated pathway. Yakugaku Zasshi 129: 1403-1413, 2009.

25. George AJ, Thomas WG and Hannan RD: The renin-angiotensin system and cancer: Old dog, new tricks. Nat Rev Cancer 10: 745-759, 2010.

26. Dougherty U, Mustafi R, Sadiq F, Almoghrabi A, Mustafi D, Kreisheh M, Sundaramurthy S, Liu W, Konda VJ, Pekow J, et al: The renin-angiotensin system mediates EGF receptor-vitamin d receptor cross-talk in colitis-associated colon cancer. Clin Cancer Res 20: 5848-5859, 2014.

27. Tamarat R, Silvestre JS, Durie M and Levy BI: Angiotensin II angiogenic effect in vivo involves vascular endothelial growth factor- and inflammation-related pathways. Lab Invest 82: 747-756, 2002.
28. Pupilli C, Lasagni L, Romagnani P, Bellini F, Mannelli M, Misciglia N, Mavilia C, Vellei U, Villari D and Serio M: Angiotensin II stimulates the synthesis and secretion of vascular permeability factor/vascular endothelial growth factor in human mesangial cells. J Am Soc Nephrol 10: 245-255, 1999.

29. Otani A, Takagi H, Oh H, Koyama S and Honda Y: Angiotensin II induces expression of the Tie2 receptor ligand, angiopoietin-2, in bovine retinal endothelial cells. Diabetes 50: 867-875, 2001.

30. Fujita M, Hayashi I, Yamashina S, Itoman M and Majima M: Blockade of angiotensin ATla receptor signaling reduces tumor growth, angiogenesis, and metastasis. Biochem Biophys Res Commun 294: 441-447, 2002.

31. Deshayes F and Nahmias C: Angiotensin receptors: A new role in cancer? Trends Endocrinol Metab 16: 293-299, 2005. 